\title{
Reading Comprehension as a Function of Text Genre and Presentation Environment: Comprehension of Narrative and Informational Texts in a Computer-Assisted Environment vs. Print
}

\author{
Baha Makhoul1,2,3, Thuraia Copti-Mshael1,3 \\ ${ }^{1}$ Oranim Academic College of Education, Tivon, Israel \\ ${ }^{2}$ The NCJW Research Institute for Innovation in Education, Hebrew University, Jerusalem, Israel \\ ${ }^{3}$ CET-Center for Educational Technology, Tel-Aviv, Israel \\ Email: Baham@cet.ac.il
}

Received 15 April 2015; accepted 23 June 2015; published 26 June 2015

Copyright (C) 2015 by authors and Scientific Research Publishing Inc.

This work is licensed under the Creative Commons Attribution International License (CC BY).

http://creativecommons.org/licenses/by/4.0/

(c) (i) Open Access

\section{Abstract}

The current study attempts to investigate the differences in reading comprehension as a function of the text's genre in a computer-assisted environment vs. print. For this purpose, data were collected from 34 fifth-grade narrative computerized unit, narrative printed unit, informational computerized unit and informational printed unit. The results pointed to an interaction effect between the text genre and presentation environment. For the informational units, better performance was noted on the computerized environment when compared to the printed. Marginal effect was encountered for the narrative units, pointing to higher reading comprehension on the printed environment. In addition, we examined whether one environment will be more beneficial than the other, when comparing poor and good comprehenders. No interaction effect was encountered between comprehension level and presentation environment. However, post-hoc analysis indicates that among the good comprehenders, better performance was achieved on the printed units. The data is discussed in terms of its implications on utilizing computerized-assisted environments as an aid in reading comprehension instruction.

\section{Keywords}

Computer-Assisted, Literacy, Reading Comprehension, Text Genre, Presentation Environment 


\section{Introduction}

In the digital era, printed texts have ceased to be the major source of information, as technological innovations are becoming a grand carrier of information. The invasion of technology has changed the face of literacy. The rapid emergence of new technologies is leading to the birth of new literacies, requiring on the one hand, its redefinition (Cammack, 2002; King \& O’Brien, 2002; Leu, Kinzer, Coiro, \& Cammack, 2004) and on the other hand, the development of the necessary skills to cope with its demands. Nowadays, educational technologies play a crucial role in literacy instruction, supplying diverse tools to cope with literate content via technological devices such as computers, smart-boards, and internet based technologies that support and shape the development of reading and writing skills, tailored to 21 st century literacy perquisites.

In the scoop of the current theoretical review, the linkage between technology and reading comprehension is explored in terms of the environment medium of presentation (computerized/printed) and the text genre (narrative/ informational).

\subsection{Literacy Education and Technology}

The technological rapid progress has left its marks on the construct of literacy and as such its instruction. Today, classroom instruction is constantly changing, relying more and more on technological innovations, that support and advance literacy acquisition. For example, the incorporation of computer assisted instruction has proven to be beneficial in supporting reading acquisition and for remedial purposes, enhancing the different skills underlying and supporting reading such as phonemic awareness, word decoding, fluency and sound-letter correspondence and reading comprehension (Blok, Oostdam, Otter \& Overmaat, 2002; MacArthur, Ferretti, Okolo \& Cavalier, 2001; Cobb, 2001; Mayer \& Moreno, 2000; Roth \& Beck, 1997; Foster, Erickson, Foster, Brinkman, \& Torgesen, 1994; Lonigan, Driscoll, Phillips, Cantor, Anthony \& Goldstein, 2003; Wise, Ring \& Olson, 2000; Kim, 2002; Makhoul, Olshtein, \& Ibrahim, 2014). However, research on the usage of computers as means to promote reading comprehension is still limited and needs further investigating.

\subsubsection{Reading Comprehension in the Era of Technology}

Reading comprehension is a core skill in the route to literacy, especially in our information age area, since it is a major competency for acquiring and using information and later inclusion in society and job markets (Hay \& Fielding-Barnsley, 2009; Moats, 2000). Throughout primary school years, grand effort is dedicated to foster and enhance strategic re5ading comprehension, recruiting technological tools to support classroom instruction that in turn exposes students to reading comprehension in various contexts they are expected to encounter later on.

As part of the changes occurring in the nature of literacy and in coincidence with the scientific insights, reading comprehension is undergoing constant re-conceptualizing, striving to encompass its underlying mechanisms and processes in the different contexts. In part, the gradually increasing shift to on-screen reading via the multitudes of available technological apparatuses has contributed to the variance in reading comprehension processes and skills.

The RAND Reading Study Group (2000) conceptualized reading comprehension as a function of the interaction between the reader, the text and reading activity that are impacted by socio-cultural values and context. Specifically, it is suggested that the reading environment in which comprehension is embedded affects the dynamics between the two core components: the reader and the text. Thus, when considering the diversity of reading environments, it is presumed that reading comprehension processes differ.

\subsubsection{Reading Comprehension: Between Digitized Environments and Print}

Throughout the years, studies that addressed the difference in reading performance in computerized versus printed medium yielded controversial results. Conceding with the prominent increase in computer usage, early comparative studies in the field reported superiority in reading performance in printed medium of presentation when compared to computerized environment noted across several reading measures: reading accuracy, fluency and comprehension (e.g. Ziefle, 1998; Dillon, 1992; Gould \& Grischkowsky, 1984; Wright \& Lickorish, 1983). On the other hand, other group of studies reported no significant effect of the texts' medium of presentation on the above-mentioned reading measures (e.g. Muter \& Maurutto, 1991; Askwall, 1985; Oborne \& Holton, 1988). Accordingly, Noyes \& Garland (2004) suggested that the deteriorative effect of screen-displayed texts on reading, 
as noted by studies conducted in the $80 \mathrm{~s}$ and $90 \mathrm{~s}$, is due to the digressed resolution of screen displays. Nowadays, with the immense technological advancements (e.g. higher resolution screens), scientific evidence points to the efficacy of CAI in promoting decoding skills and reading comprehension (Makhoul et al., 2014; Mitchell \& Fox, 2001; Wise \& Olson, 2000).

In part, the incorporation of computer-assisted instruction enables exposure to reading comprehension processes in different contexts, supplying the pupils with required tools and strategies to cope with the specific characteristics of each text genre. Additionally, such environments can be employed to support reading comprehension skills as a result of the diverse features it incorporates, allowing modification and enhancements that fosters reading comprehension and learning (Meyer \& Rose, 2005; Kamil, Intrator, \& Kim, 2000; Leu, 2000; Anderson-Inmana \& Homey, 2007). Main features of computerized reading environments are presented below:

1. Digitalized speech: Electronic texts might be accompanied by auditory narration of the text that might contribute to improving word decoding and comprehension and reducing the cognitive effort invested in decoding, thus allowing allocation of effort to construct meaning (Hartas \& Moseley 1993; Lewin, 2000; Matthew, 1997; Miller, Blackstock \& Miller, 1994). Additionally, Digitalized speech enables incorporation of beneficial instructional practices such as scaffolding, corrective feedback and immediate evaluation of performance (Ellis \& Worthington, 1994; Elbro, Rasmussen \& Spelling, 1996). Indeed, synthesized feedback has been shown to improve word-decoding skills among struggling readers, reduces the cognitive load resulting from decoding and induces success experience that in turn enhances motivation (e.g. Olson \& Wise, 1992; Wise, Olson, Ring \& Johnson, 1998; Forgrave, 2002; Montali \& Lewandowski, 1996).

2. Text enhancements: Electronic texts might be accompanied by illustrations, videos, passage paraphrases, background information and font size modification, adjusted to the needs of the reader, which ultimately aid in promoting comprehension (Reinking \& Schreiner, 1985; Greenlee- Moore \& Smith, 1996). Additionally, facilitating functions such word definitions, proofing tools, copy-paste functions can be included.

3. Internet accessibility: computerized learning environments offers accessibility to the multitudinous of information resources available online such dictionaries, encyclopedias, scientific articles and other types of media. Access to sources of information might contribute to text comprehension by enriching background knowledge. Prior knowledge is thought to play a crucial role in comprehension process, especially in informational texts requiring domain-specific knowledge (e.g. Adams, Bell, \& Perfetti, 1995; Coiro \& Dubler, 2007; Alexander, Kulikowich, \& Schulze, 1994; Means \& Voss, 1985; Snow, 2002; Beck, McKeown, Sinatra, \& Loxterman, 1991; Graesser, Leon, \& Otero, 2002).

Accordingly, due to the bimodal nature of computerized environment, it is thought to enhance reading skills by fostering letter-sound correspondence and giving feedback regarding the accuracy of decoding, which in turn improves reading automaticity and comprehension (e.g. Montali \& Lewandowski, 1996; MacArthur, Ferretti, Okolo, \& Cavalier 2001; Olson \& Wise, 1992). In their study, Montali \& Lewandowski (1996) examined the effect of simultaneous bimodal exposure to passages presented in computerized environment on comprehension by comparing reading comprehension performance of poor readers in three conditions: visually, auditory (speech synthesis) and simultaneous auditory-visual presentation. The results of the study pointed to an optimal reading comprehension performance in the bimodal condition, where the performance of less skilful readers was enhanced to match their control counterparts. Additionally, both poor readers and control group reported higher preference of the bimodal medium of presentation.

Another advantage for computerized environment is its impact on motivation. Computer-assisted environment have been found to enhance learning motivation (Makhoul, Olshtein, \& Ibrahim, 2014). Extensive scientific efforts have established the causality between reading motivation and reading performance (e.g. Gambrell, 2001; Guthrie, Wigfield, Metsala, \& Cox, 1999). Features encountered in computerized environments such as graphics, animations, sound effects and video inspires more enjoyable reading experience and engagement with the text, affecting reading and comprehension performance (Grimshaw, Dungworth, McKnight, \& Anne Morris, 2007).

In conclusion, it is worthy to note that despite the advantages of a computerized environment and the above presented argumentations, its superiority over printed presentation is still controversial, some pointing to no difference in reading comprehension between the two manners of presentation. For example, in their study, Sorrell, Bell \& McCallum (2007), examined the benefice of computerized-assisted reading to improving reading comprehension among elementary school-aged weak readers, compared to traditional instruction. No difference was encountered in overall reading comprehension scores after computer-assisted reading. Furthermore, it was proposed that reading hypertexts might hinder reading comprehension since it tends to induce cognitive load (DeS- 
tefano \& LeFevre, 2007). In their review, addressing the equivalency between the two environments, Noyes and Garland (2008) concluded that difference in coping with reading activities in the two environments-computerized and printed-resides in the adequacy of each environment to the specific task in hand and its outcome where for a certain task one environment might be superior to the other. In addition, it has been suggested that the sole presentation of the text in a computerized environment is not sufficient to enhance reading comprehension (Twyman \& Tindal, 2006).

\subsection{Reading Comprehension as a Function of Genre}

Text genre is one of the factors influencing reading comprehension. Awareness and familiarity with text genres is essential in the road to obtaining meaning since it dictates the reader's anticipation regarding the manner of ideas and information's enfoldment in the text (RAND Study Group, 2002; Meyer, 2003). In addition to decoding skills, general knowledge, linguistic competencies, semantics and orthographical knowledge, reading comprehension is subject to comprehension processes that rely on structure sensitivity and texts' mental representation (Perfetti, Landi, \& Oakhill, 2005).

Already in childhood, children are familiarized with narrative text structure, gaining awareness to its features, which in turn facilitates their understanding of stories. In contrast, informational texts are mainly addressed in advanced stages of primary instruction. Additionally, unlike the overall standardized and familiar structure of narrative texts, informational texts are varied in their structure and incorporate different features, complex linguistic constructs and vocabulary that solicits different requirements from the reader and adds another layer of difficulty in arriving to comprehension (Kucan \& Beck, 1997; Yopp \& Yopp, 2002; Berman \& Katzenberger, 2004). Previous findings indicate that in comparison to narrative texts, fluency and comprehension is reduced when reading informational texts (e.g. Parmar et al., 1994; Sáenz \& Fuchs, 2002).

\section{Reading Comprehension: Between Digitized Environments and Print}

In light of the above-depicted advantages encountered in computerized environment, one can assume that technology can facilitate and bridge the gaps in literacy acquisition, especially in complex orthographies. Specifically, when considering the case of Diglossic Arabic, it is thought to be one of the most controversial languages to be acquired due to its socio-linguistic constraints. On the one hand, the impact of the Diglossic nature of Arabic (i.e. the linguistic discrepancy between its spoken and literary form) on literacy acquisition has been extensively documented (Ayari, 1996; Khamis-Dakwar \& Froud, 2007; Ibrahim, 2009). On the other hand, the orthographic complexity of Arabic sets yet another impediment for reading acquisition, due to the induced visual load during visual processing of words, leading to slower word identification (Abdelhadi, Ibrahim, \& Eviatar, 2011; Eviatar, Ibrahim, \& Ganayim, 2004).

Accordingly, it is presumed that bimodal facilitation and text enhancements, as offered by computerized environments, might be utilized as a compensating factor, assisting in overcoming the complexities of Arabic orthography and improving decoding and reading comprehension skills. The investigation of technology role in Arabic reading instruction has only incited lately, drawing on the additive learning value of computer assisted instruction that might contribute to overcome the obstacles hindering Arabic reading acquisition. In one study, Makhoul, Olshtein, and Ibrahim (2014) investigated the effect of a balanced interactive computer assisted promoting reading comprehension skills among at-linguistic risk Arab first graders. The results of the study pointed to a significant improvement in comprehension skills among children in the intervention group when compared to comparison group.

\subsection{The Current Study}

So far, scientific research has focused on investigating the effect of computer-assisted environments on reading literacy. However, no other study has directly attempted to investigate the suitability of computer-assisted environment to cope with different text genres.

Hence, the current study will attempt to investigate for the first time reading comprehension performance of fifth graders, after completing their reading acquisition process in two environments: printed vs. computerized. Additionally, it will investigate performance difference across two text genres.

The study questions: 
1. Is there a difference in the pupils' reading comprehension performance in the computerized environment when compared to printed environment?

2. Is there a difference in the pupils' reading performance when dealing with narrative texts compared to informational texts in each of the environments?

3. Which environment will be more beneficial for poor comprehenders when compared to good comprehenders?

4. Is there a correlation between the pupils' presentation environment preference and reading comprehension achievements?

\section{Method}

\subsection{Participants}

Fifty-five Arabic native speaker fifth graders from an elementary school in Israel center area participated in the study (23 boys and 32 girls) $(M=10.8, S D=5.97)$. It should be noted that only 34 students completed all the four units.

As part of their Arabic classroom instruction, all the selected participants used "Arabic is our language" textbooks series, developed by the team of Arabic language in the Center of Educational Technology (CET) drawing on the principles of balanced interactive learning. Additionally, the sampled school was part of two years ongoing project of school technology immersion where every pupil was equipped by a personal laptop. To enable successful implementation, teachers have been participating for three years in a weekly training session, carried out by an instructor of digital content development from CET that aims to facilitate the integration of computer assisted learning, provide tools and knowledge of the digital environment and ideas for integrating digital tools in the teaching process. Alongside the training, the instructor monitored the teachers' ability to implement the acquired knowledge, and supervised the incorporated digital tool in their lesson plans.

\subsection{Measures}

1. For the purpose of the current study, four reading comprehension units were developed: narrative computerized unit, informational computerized unit, narrative printed unit and informational printed unit (See Table 1).

2. On each unit, a text was presented, followed by comprehension questions, addressing the four comprehension levels as proposed in PIRLS-Progress in International Reading Literacy-theoretical framework (2006), in addition to exercises evaluating (see Table 2) linguistic knowledge (Phonology, morphology, syntax, spelling and punctuation). Both close-ended and open-ended questions were included (multiple choice, cloze, matching and dragging). Scoring was assigned on 100 points scale where partial answers and wrong answers received 50 and 0 points on the open-ended questions, respectively. On the closed-ended questions, each correct answer granted 100 points. For each unit, an average score was calculated.

3. Student's questionnaire: The pupils filled a feedback questionnaire, containing six statements describing their performance level on both environments and their preferences. The students were asked to rate on a Likert scale their agreement degree to the presented statements (1-little to 6-to a great extent). For example, "I found it difficult to solve the computerized unit".

4. Observational documentations for qualitative impression on the quantitative data performed by the accompanying teacher.

\section{Results}

\subsection{Differences in the Pupils' Reading Comprehension Performance in the Computerized Environment When Compared to Printed Environment}

Two-way analysis of Variance revealed no significant t for the task environment $[F<1]$ on reading comprehension performance. No significant difference was encountered in the pupils' reading comprehension scores in the computerized environment $(M=5.86, S D=3.62)$ when compared to printed $(M=58.13, S D=3.21)$ (See Figure 1). 


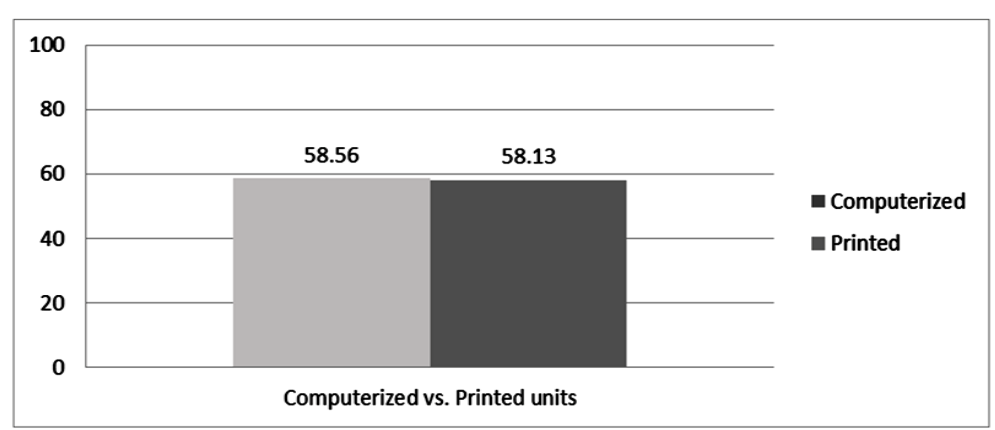

Figure 1. The pupils' comprehension performance on the computerized vs. the printed environment.

Table 1. Units description as a function of text genre and medium of presentation.

\begin{tabular}{|c|c|c|c|c|c|c|c|}
\hline & \multicolumn{3}{|c|}{ Narrative } & \multicolumn{4}{|c|}{ Informational } \\
\hline \multirow[t]{2}{*}{ Computerized } & \multicolumn{3}{|c|}{ “Taha Hussein” } & \multicolumn{4}{|c|}{ "Trip in the nature" } \\
\hline & \multicolumn{3}{|c|}{$\begin{array}{l}\text { An autobiography of the Egyptian author } \\
\text { Taha Hussien. The text included } 741 \text { words } \\
\text { and was accompanied by pictures } \\
\text { illustrating the content of the text and } \\
\text { an s digitized narration function. } \\
\text { Seventeen questions were included. }\end{array}$} & \multicolumn{4}{|c|}{$\begin{array}{l}\text { The text contained } 776 \text { words and it is divided into two parts: } \\
\text { the first part of the text displays information and tips how to } \\
\text { choose a nature trail, the second part of the text has a real description of a } \\
\text { nature trail in Israel in accordance with the criteria presented in the first } \\
\text { part. Alongside photographs that illustrate the text and an audio for } \\
\text { listening to the text. The text was accompanied by } 13 \text { questions }\end{array}$} \\
\hline \multirow[t]{2}{*}{ Printed } & \multicolumn{3}{|c|}{ “Mahmoud Abbassi” } & \multicolumn{4}{|c|}{ “Chess” } \\
\hline & \multicolumn{3}{|c|}{$\begin{array}{l}\text { An autobiography of a local Arab writer. } \\
\text { The text consisted of } 623 \text { words. } \\
\text { Illustrations were also included. } \\
\text { The text was followed by } 21 \text { questions. }\end{array}$} & \multicolumn{4}{|c|}{$\begin{array}{l}\text { The text contained } 659 \text { words. The text describes chess game, } \\
\text { its advantage and the games structure and rules. The text was } \\
\text { accompanied by illustration. } 17 \text { questions were included. }\end{array}$} \\
\hline Text $\mathbf{T}$ & & Environment & Genre & Verbal & Explicit & Implicit & Linguistic Knowledge \\
\hline Taha Hus & sein & Computer & Narrative & 2 & 9 & 2 & 4 \\
\hline Mahmoud & bbassi & Printed & Narrative & 7 & 8 & 2 & 4 \\
\hline Trip in $\mathrm{N}$ & ture & Computer & Informational & 2 & 5 & 5 & 1 \\
\hline Ches & & Printed & Informational & 4 & 10 & 5 & 3 \\
\hline
\end{tabular}

\subsection{Differences in the Pupils' Reading Comprehension as a Function of Text Genre}

No significant difference was encountered in the pupils' overall performance on the narrative units $(M=57.17$, $S D=3.42)$ when compared to informational units, $(M=59.52, S D=3.44)$, [F < 1] (See Figure 2).

\subsection{Differences in the Pupils' Reading Comprehension as a Function of Text Genre and Presentation Environment}

Two-way analysis of variance revealed a significant interaction effect between the text genre and presentation environment $[F(1,33)=8.53, M S E=195.01, p<.01]$. For the informational units, a significant difference was encountered between the pupils' performance on the computerized $(M=63.23, S D=4.38)$ and printed based environment $(M=53.89, S D=3.73)$, where significantly higher average score was obtained on the former ( $t$ (39) $=-2.31, p<.05$ ) (See Figure 2). In contrast, on the narrative units, only Marginal difference in the pupils' performance was found between the computerized and printed units $(t(45)=2.03, p<.05)$. The pupils' performance was slightly higher on the printed environment $(M=60.46, S D=3.7)$ when compared to the computerized $(M=53.89, S D=3.73)$ (See Figure 3). 


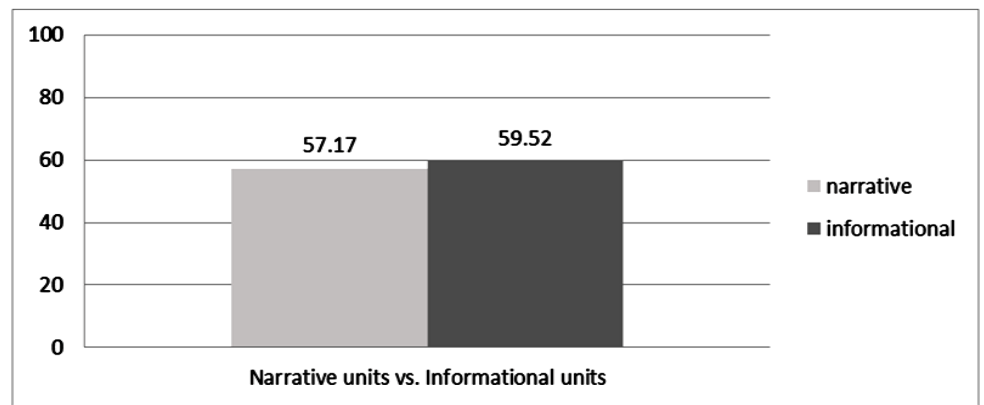

Figure 2. The pupils' comprehension performance on the narrative units vs. the informational units.

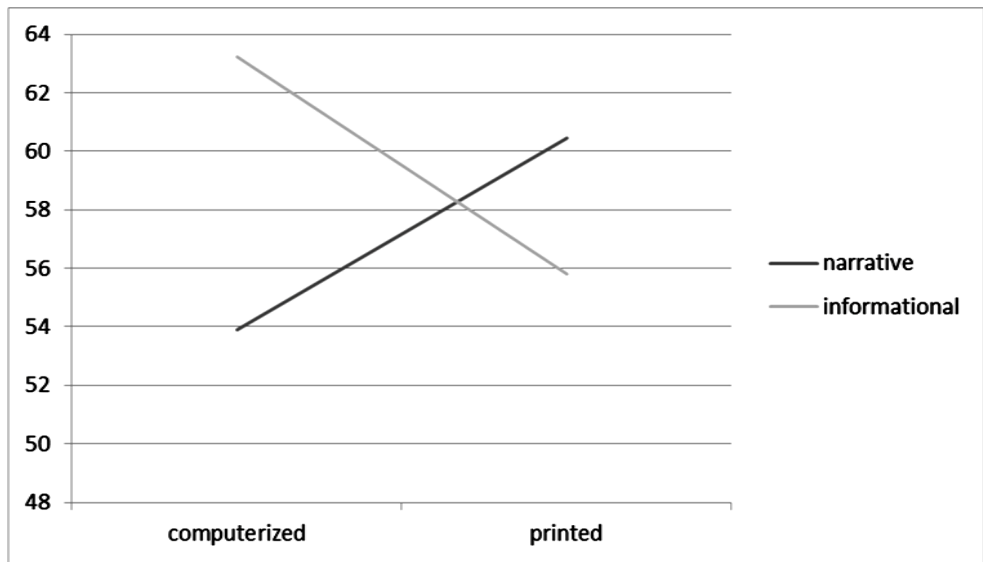

Figure 3. Pupils' performance in reading comprehension as a function of text genre and presentation environment.

Good and Poor Comprehenders' Performance in Different Genres as a Function of Presentation Environment

In accordance with the pupils' overall mean score (i.e. composed of their scores on the four units), two groups of comprehenders were created: poor $(M<70)$ and good comprehenders $(M \geq 70)$. Independent samples T-test pointed to a significant difference between the two groups in reading comprehension overall score $(t(25)=$ -7.048, $p<.001)$. The good comprehenders performed significantly better than the poor comporehenders in both the computerized units $(t(25)=-5.99, p<.001)$ and the printed units $(t(25)=-5.05, p<.001)$. In addition, good comprehenders outperformed the bad comprehenders in both the narrative units $(t(25)=-4.86, p<.001)$ and printed units $(t(25)=-6.12, p<.001)$ (See Table 3 ).

To examine the combined effect of presentation environment and text genre on the performance of each group, three-way-analysis of variance was conducted. No interaction effect was encountered between comprehension level, text genre and presentation environment $(F<1)$. However, post-hoc analysis revealed that for the good comprehenders, performance was significantly higher on the printed environment, on both the narrative units and the informational units, $(t(15)=2.74, p<.05),(t(26)=-2.96, p<.05)$, respectively.

\subsection{Description of the Pupils' Working Environment Preference and Correlation with Reading Comprehension Performance}

The pupil's self-rating on the preference questionnaire revealed that higher percentage of pupils prefers the computerized environment in learning processes. On average, $57.1 \%$ of the students expressed their preference of the computerized environment (See Figure 4).

To examine the relation between the pupils' preference and performance in reading comprehension, Pearson correlation was calculated. No significant correlation was encountered between the pupils' preference and reading comprehension performance on $(r=-0.05, p$. ns). 


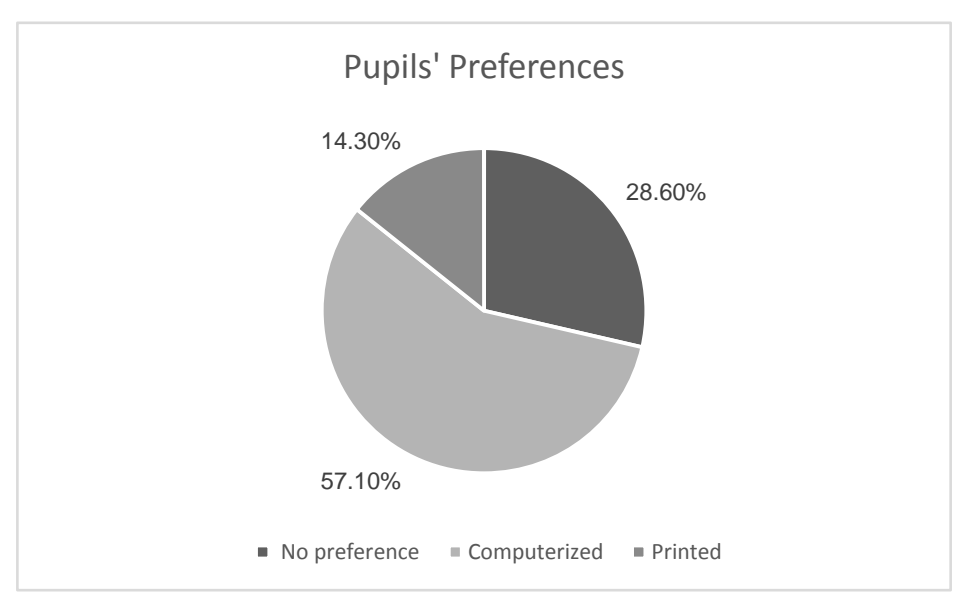

Figure 4. The pupils' learning environment preferences.

Table 3. Comparison between poor and good comprehenders ( Reading comprehension Mean scores, Standard deviations, Ttest scores and $\mathrm{P}$ value across genre type and presentation environment and comprehension level).

\begin{tabular}{ccccc}
\hline & $\begin{array}{c}\text { Poor Comprehenders (n = 11) } \\
\text { M (SD) }\end{array}$ & $\begin{array}{c}\text { Good Comprehenders (n= 16) } \\
\text { M (SD) }\end{array}$ & T-test & $p$ value \\
\hline Printed units & $52.51(11.59)$ & $73.47(9.23)$ & -5.23 & $p<.001^{* * *}$ \\
Computerized units & $53.98(8.35)$ & $75.60(10.38)$ & -5.74 & $p<.001^{* * *}$ \\
Narrative units & $52.98(11.76)$ & $72.84(9.42)$ & -4.86 & $p<.001^{* * *}$ \\
Informational units & $53.5(8.68)$ & $76.23(9.97)$ & -6.12 & $p<.001^{* * *}$ \\
All average & $53.24(8.34)$ & $75.60(10.37)$ & -7.05 & $p<.001^{* * *}$ \\
\hline
\end{tabular}

\section{Discussion}

Contrary to our expectations and to previous findings, no significant differences were found in coping with narrative texts when compared to informational texts. The equivalency of both genre types may be attributed to Arabic diglossic nature, where the discrepancy between its spoken and written form affects students' reading comprehension performance, across the different text genres, both differing greatly in their vocabulary repertoire and linguistic construct if presented in spoken Arabic.

The results of the current study did not yield clear cut conclusion regarding the supremacy of neither the computerized nor the printed based environment where no significant difference was encountered in reading comprehension performance between the two environments. The current results falls in line with Noyes and Garland (2004) conclusions, pointing to no differences in reading comprehension and reading time in computerized vs. printed medium of presentation.

However, in the current study, an interaction effect was encountered between the texts' genre type and its medium of presentation. In narrative units, although only marginal effect was encountered, better performance was noted in the printed environment when compared to the computerized environment. In contrast, in the informational units, there was a significant difference when comparing the performance of the pupils in the computerized environment to the printed environment; the pupils performed better in the computerized unit.

Despite the fact that no significant effect was encountered in reading comprehension performance between informational and narrative texts, the interaction effect as encountered in our study, suggest to the involvement of different reading comprehension process, set by the demands of each genre type. Furthermore, the results points to significant differences between the three achievers sub-groups, across genre type and task environment where no effect of the task environment was encountered among the low-achieving students. Accordingly, This results show that neither task environment helped the struggling pupils to bridge the gap with the other pupils.

Another important issue that our results raise is the relationship between the Pupils' presentation environment 
preference and actual achievements. The results of the current study did not encounter any significant correlation between the pupils' preferences and achievements. Due to the limitation of the small sample size, any conclusion should be treated carefully. Hence, future study is required to investigate whether the pupils' preferences affect their reading comprehension achievements.

\section{Conclusion}

In conclusion, the benefice of each medium of presentation needs to be further explored, taking into account individual differences and task demands. Further study is needed in order to map the different comprehension process when dealing with the variant genre types across different environments. Also, in order to arrive to clearer conclusions, bigger sample of participants is needed.

\section{References}

Abdelhadi, S., Ibrahim, R., \& Eviatar, Z. (2011). Perceptual Load in the Reading of Arabic: Effects of Orthographic Visual Complexity on Detection. Writing Systems Research, 3, 117-127. http://dx.doi.org/10.1093/wsr/wsr014

Adams, B. C., Bell, L. C., \& Perfetti, C. A. (1995). A Trading Relationship between Reading Skill and Domain Knowledge in Children's Text Comprehension. Discourse Processes, 20, 307-323. http://dx.doi.org/10.1080/01638539509544943

Alexander, P. A., Kulikowich, J. M., \& Schulze, S. K. (1994). The Influence of Topic Knowledge, Domain Knowledge, and Interest on the Comprehension of Scientific Exposition. Learning and Individual Differences, 6, 379-397. http://dx.doi.org/10.1016/1041-6080(94)90001-9

Anderson-Inman L., \& Homey M. A. (2007). Supported eText: Assistive Technology through Text Transformations. Reading Research Quarterly, 42, 153-160. http://dx.doi.org/10.1598/RRQ.42.1.8

Askwall, S. (1985). Computer Supported Reading vs Reading Text on Paper: A Comparison of Two Reading Situations. International Journal of Man-Machine Studies, 22, 425-439. http://dx.doi.org/10.1016/S0020-7373(85)80048-1

Ayari, S. (1996). Diglossia and Illiteracy in the Arab World. Language, Culture and Curriculum, 9, 243-253. http://dx.doi.org/10.1080/07908319609525233

Beck, I. L., McKeown, M. G., Sinatra, G. M., \& Loxterman, J. A. (1991). Revising Social Studies Text from a TextProcessing Perspective: Evidence of Improved Comprehensibility. Reading Research Quarterly, 26, 251-276. http://dx.doi.org/10.2307/747763

Berman, R. A., \& Katzenberger, I. (2004). Form and Function in Introducing Narrative and Expository Texts: A Developmental Perspective. Discourse Processes, 38, 57-94. http://dx.doi.org/10.1207/s15326950dp3801_3

Blok, H., Oostdam, R., Otter, M. E., \& Overmaat, M. (2002). Computer-Assisted Instruction in Support of Beginning Reading Instruction: A Review. Review of Educational Research, 72, 101-130. http://dx.doi.org/10.3102/00346543072001101

Cammack, D. W. (2002). Literacy, Technology, and a Room of Her Own: Analyzing Adolescent Girls' Online Conversations from Historical and Technological Literacy Perspectives. In D. Schallert, C. Fairbanks, J. Worthy, B. Maloch, \& J. Hoffman (Eds.), Fifty-First Yearbook of the National Reading Conference (pp. 129-141). Chicago: National Reading Conference.

Cobb, J. B. (2001). The Effects of an Early Intervention Program with Preservice Teachers as Tutors on the Reading Achievement of Primary Grade at Risk Children. Reading Horizons, 41, 155-173.

Coiro, J., \& Dobler, E. (2007). Reading Comprehension on the Internet: Exploring the Online Comprehension Strategies Used by Sixth-Grade Skilled Readers to Search for and Locate Information on the Internet. Reading Research Quarterly, 42, 214-257. http://dx.doi.org/10.1598/RRQ.42.2.2

DeStefano, D., \& LeFevre, J. A. (2007). Cognitive Load in Hypertext Reading: A Review. Computers in Human Behavior, 23, 1616-1641. http://dx.doi.org/10.1016/j.chb.2005.08.012

Dillon, A. (1992). Reading from Paper versus Screens: A Critical Review of the Empirical Literature. Ergonomics, 35, 12971326. http://dx.doi.org/10.1080/00140139208967394

Elbro, C., Rasmussen, I., \& Spelling, B. (1996). Teaching Reading to Disabled Readers with Language Disorders: A Controlled Evaluation of Synthetic Speech Feedback. Scandinavian Journal of Psychology, 37, 140-155. http://dx.doi.org/10.1111/j.1467-9450.1996.tb00647.x

Ellis, E. S., \& Worthington, L. A. (1994). Executive Summary of Research Synthesis on Effective Teaching Principles and the Design of Quality Tools for Educators. Eugene, OR: National Center to Improve the Tools of Educators, College of Education, University of Oregon.

Eviatar, Z., Ibrahim, R., \& Ganayim, D. (2004). Orthography and the Hemispheres: Visual and Linguistic Aspects of Letter Processing. Neuropsychology, 18, 174-184. http://dx.doi.org/10.1037/0894-4105.18.1.174 
Forgrave, K. (2002). Assistive Technology: Empowering Students with Learning Disabilities. The Clearing House, 75, 122126. http://dx.doi.org/10.1080/00098650209599250

Foster, K. C., Erickson, G. C., Foster, D. F., Brinkman, D., \& Torgeson, J. K. (1994). Computer Administered Instruction in Phonological Awareness: Evaluation of the Daisy Quest Program. The Journal of Research and Development in Education, 27, 126-137.

Gambrell, L. B. (2001). What We Know about Motivation to Read. In R. F. Flippo (Ed.), Reading Researchers in Search of Common Ground (pp. 129-143). Newark, DE: International Reading Association.

Gould, J. D., \& Grischkowsky, N. (1984). Doing the Same Work with Hard Copy and with Cathode-Ray Tube (CRT) Computer Terminals. Human Factors: The Journal of the Human Factors and Ergonomics Society, 26, 323-337.

Graesser, A. C., León, J. A., \& Otero, J. (2002). Introduction to the Psychology of Science Text Comprehension. In J. Otero, J. A. Leon, \& A. C. Graesser (Eds.), The Psychology of Science Text Comprehension (pp. 1-15). Mahwah, NJ: Erlbaum.

Greenlee-Moore, M. E., \& Smith, L. L. (1996). Interactive Computer Software: The Effects on Young Children’s Reading Achievement. Reading Psychology: An International Quarterly, 17, 43-64.

http://dx.doi.org/10.1080/0270271960170102

Grimshaw, S., Dungworth, N., McKnight, C., \& Morris, A. (2007). Electronic Books: Children’s Reading and Comprehension. British Journal of Educational Technology, 38, 583-599. http://dx.doi.org/10.1111/j.1467-8535.2006.00640.x

Guthrie, J. T., Wigfield, A., Metsala, J. L., \& Cox, K. E. (1999). Motivational and Cognitive Predictors of Text Comprehension and Reading Amount. Scientific Studies of Reading, 3, 231-256. http://dx.doi.org/10.1207/s1532799xssr0303 3

Hartas, C., \& Moseley, D. (1993). "Say That Again, Please”: A Scheme to Boost Reading Skills Using a Computer with Digitised Speech. Support for Learning, 8, 16-21. http://dx.doi.org/10.1111/j.1467-9604.1993.tb00112.x

Hay, I., \& Fielding-Barnsley, R. (2009). Competencies That Underpin Children's Transition into Early Literacy. Australian Journal of Language and Literacy, 32, 148-162.

Ibrahim, R. (2009). The Cognitive Basis of Diglossia in Arabic: Evidence from a Repetition Priming Study within and between Languages. Psychology Research and Behavior Management, 2, 93-105. http://dx.doi.org/10.2147/PRBM.S5138

Kamil, M. L., Intrator, S. M., \& Kim, H. S. (2000). The Effects of Other Technologies on Literacy and Literacy Learning. In M. L. Kamil, P. B. Mosenthal, P. D. Pearson, \& R. Barr (Eds.), Handbook of Reading Research (Vol. III, pp. 771-788). Mahwah, NJ: Erlbaum.

Khamis-Dakwar, R., \& Froud, K. (2007). Lexical Processing in Two Language Varieties: An Event-Related Brain Potential Study of Arabic Native Speakers. In M. Mughazy (Ed.), Perspectives on Arabic Linguistics (Vol. XX, pp. 153-168). Amsterdam \& Philadelphia, PA: John Benjamins. http://dx.doi.org/10.1075/cilt.290.13kha

Kim, M. (2002). The Use of the Computer in Developing L2 Reading Comprehension: Literature Review and Its Implications. ERIC Document Reproduction Service No. 472671.

King, J., \& O’Brien, D. (2002). Adolescents’ Multiliteracies and Their Teachers’ Needs to Know: Toward a Digital Detente. In D. E. Alvermann (Ed.), Adolescents and Literacies in a Digital World (pp. 40-50). New York: Peter Lang.

Kucan, L., \& Beck, I. L. (1997). Thinking Aloud and Reading Comprehension Research: Inquiry, Instruction, and Social Interaction. Review of Educational Research, 67, 271-299.

Leu, D. J., Kinzer, C. K., Coiro, J. L., \& Cammack, D. W. (2004). Toward a Theory of New Literacies Emerging from the Internet and Other Information and Communication Technologies. Theoretical Models and Processes of Reading, 5, 15701613.

Lewin, C. (2000). Exploring the Effects of Talking Book Software in UK Primary Classrooms. Journal of Research in Reading, 23, 149-157. http://dx.doi.org/10.1111/1467-9817.00111

Lonigan, C. J., Driscoll, K., Phillips, B. M., Cantor, B. G., Anthony, J. L., \& Goldstein, H. (2003). A Computer-Assisted Instruction Phonological Sensitivity Program for Preschool Children At-Risk for Reading Problems. Journal of Early Intervention, 25, 248-262. http://dx.doi.org/10.1177/105381510302500402

MacArthur, C. A., Ferretti, R. P., Okolo, C. M., \& Cavalier, A. R. (2001). Technology Applications for Students with Literacy Problems: A Critical Review. The Elementary School Journal, 101, 273-301. http://dx.doi.org/10.1086/499669

Makhoul, B., \& Ibrahim, R. (2014). Could an Interactive-Balanced Environment for Reading Acquisition Overcome the Triad Risk Factors: Low Socioeconomic Status, Low Literacy Skills and Language Properties? Psychology, 5, $2200-2217$. http://dx.doi.org/10.4236/psych.2014.519222

Makhoul, B., Olshtain, E., \& Ibrahim, R. (2014). Let’s Read Together: A Balanced Computer Assisted Intervention Program and Its Effect on Comprehension amongst at Linguistic Risk Arab First Graders. Journal of Advances in Linguistics, 5, 626-645. http://cirworld.org/journals/index.php/jal/article/view/3505

Matthew, K. (1997). A Comparison of the Influence of Interactive CD-ROM Storybooks and Traditional Print Storybooks on Reading Comprehension. Journal of Research on computing in Education, 29, 263-275. 
Mayer, R. E., \& Moreno, R. (2000). A Learner-Centered Approach to Multimedia Explanations: Deriving Instructional Design Principles from Cognitive Theory. Interactive Multimedia Electronic Journal of Computer-Enhanced Learning. http://imej.wfu.edu/articles/2000/2/05/index.asp

Means, M. L., \& Voss, J. F. (1985). Star Wars: A Developmental Study of Expert and Novice Knowledge Structures. Journal of Memory and Language, 24, 746-757. http://dx.doi.org/10.1016/0749-596X(85)90057-9

Meyer, B. J. (2003). Text Coherence and Readability. Topics in Language Disorders, 23, 204-224. http://dx.doi.org/10.1097/00011363-200307000-00007

Meyer, A., \& Rose, D. H. (2005). The Future Is in the Margins: The Role of Technology and Disability in Educational Reform. In D. H. Rose, A. Meyer, \& C. Hitchcock (Eds.), The Universally Designed Classroom: Accessible Curriculum and Digital Technologies (pp. 13-35). Cambridge, MA: Harvard Education Press

Miller, L., Blackstock, J., \& Miller, R. (1994). An Exploratory Study into the Use of CD-ROM Storybooks. Computers \& Education, 22, 187-204. http://dx.doi.org/10.1016/0360-1315(94)90087-6

Mitchell, M. J., \& Fox, B. J. (2001). The Effects of Computer Software for Developing Phonological Awareness in Low-Progress Readers. Literacy Research and Instruction, 40, 315-332. http://dx.doi.org/10.1080/19388070109558353

Moats, L. C. (2000). Speech to Print: Language Essentials for Teachers. Baltimore, MD: Paul H. Brookes Publishing Co.

Montali, J., \& Lewandowski, L. (1996). Bimodal Reading: Benefits of a Talking Computer for Average and Less Skilled Readers. Journal of Learning Disabilities, 29, 271-279. http://dx.doi.org/10.1177/002221949602900305

Muter, P., \& Maurutto, P. (1991). Reading and Skimming from Computer Screens and Books: The Paperless Office Revisited? Behaviour \& Information Technology, 10, 257-266. http://dx.doi.org/10.1080/01449299108924288

Noyes, J. M., \& Garland, K. J. (2008). Computer- vs. Paper-Based Tasks: Are They Equivalent? Ergonomics, 51, 1352-1375. http://dx.doi.org/10.1080/00140130802170387

Noyes, J., Garland, K., \& Robbins, L. (2004). Paper-Based versus Computer-Based Assessment: Is Workload Another Test Mode Effect? British Journal of Educational Technology, 35, 111-113.

http://dx.doi.org/10.1111/j.1467-8535.2004.00373.x

Oborne, D. J., \& Holton, D. (1988). Reading from Screen versus Paper: There Is No Difference. International Journal of Man-Machine Studies, 28, 1-9. http://dx.doi.org/10.1016/S0020-7373(88)80049-X

Olson, R. K., \& Wise, B. W. (1992). Reading on the Computer with Orthographic and Speech Feedback. Reading and Writing, 4, 107-144. http://dx.doi.org/10.1007/BF01027488

Parmar, R. S., Deluca, C. B., \& Janczak, T. M. (1994). Investigations into the Relationship between Science and Language Abilities of Students with Mild Disabilities. Remedial and Special Education, 15, 117-126. http://dx.doi.org/10.1177/074193259401500207

Perfetti, C. A., Landi, N., \& Oakhill, J. (2005). The Acquisition of Reading Comprehension Skill. In M. J. Snowling, \& C. Hulme (Eds.), The Science of Reading: A Handbook (pp. 227-247). Oxford: Blackwell Publishing Ltd. http://dx.doi.org/10.1002/9780470757642.ch13

RAND Reading Study Group (Snow, C., Chair) (2002). Reading for Understanding, Toward an R\&D Program in Reading Comprehension. Santa Monica: RAND.

Reinking, D., \& Schreiner, R. (1985). The Effects of Computer-Mediated Text on Measures of Reading Comprehension and Reading Behavior. Reading Research Quarterly, 20, 536-552. http://dx.doi.org/10.2307/747941

Ross, C. S. (2002). Reading in a Digital Age. In G. E. Gorman (Ed.), The Digital Factor in Library and Information Services (pp. 91-111). International Yearbook of Library and Information Management 2002/2003, London: Facet Publishing.

Roth, S. F., \& Beck, I. L. (1997). Theoretical and Instructional Implications of the Assessment of Two Microcomputer Word Recognition Programs. Reading Research Quarterly, 22, 197-218. http://dx.doi.org/10.2307/747665

Sáenz, L. M., \& Fuchs, L. (2002). Examining the Reading Difficulty of Secondary Students with Learning Disabilities: Expository versus Narrative Text. Remedial and Special Education, 23, 31-41. http://dx.doi.org/10.1177/074193250202300105

Snow, C. (2002). Reading for Understanding: Toward an R\&D Program in Reading Comprehension. Santa Monica, CA: RAND Corporation.

Sorrell, C. A., Bell, S. M., \& McCallum, R. S. (2007). Reading Rate and Comprehension as a Function of Computerized versus Traditional Presentation Mode: A Preliminary Study. Journal of Special Education Technology, 22, 1-12.

Twyman, T., \& Tindal, G. (2006). Using a Computer-Adapted Conceptually Based History Text to Increase Comprehension and Problem-Solving Skills of Students with Disabilities. Journal of Special Education Technology, 21, 5-16.

Wise, B. W., Olson, R. K., Ring, J., \& Johnson, M. (1998). Interactive Computer Support for Improving Phonological Skills. In J. L. Metsala, \& L. C. Ehri (Eds.), Word Recognition in Beginning Literacy (pp. 189-208). Mahwah, NJ: Lawrence Erlbaum Associates. 
Wise, B. W., Ring, J., \& Olson, R. K. (2000). Individual Differences in Gains from Computer-Assisted Remedial Reading. Journal of Experimental Child Psychology, 77, 197-235. http://dx.doi.org/10.1006/jecp.1999.2559

Wright, P., \& Lickorish, A. (1983). Proof-Reading Texts on Screen and Paper. Behavior \& Information Technology, 2, 227235. http://dx.doi.org/10.1080/01449298308914479

Yopp, H. K., \& Yopp, R. H. (2002). Ten Important Words: Identifying the Big Ideas in Informational Text. Journal of Content Area Reading, 2, 7-13.

Ziefle, M. (1998). Effects of Display Resolution on Visual Performance. Human Factors: The Journal of the Human Factors and Ergonomics Society, 40, 554-568. http://dx.doi.org/10.1518/001872098779649355 